\title{
Effects of cardiopulmonary bypass on narrow-pore flow behavior of blood
}

\author{
Krister Lindmark, MD, PhD, and K. Gunnar Engström, MD, PhD, Umeå, Sweden
}

$\mathrm{T}$ he possible link with cognitive changes caused by arterial microembolization during cardiopulmonary bypass (CPB) drives cardiac surgery toward off-pump procedures. One of these CPB effects is blood trauma. CPB indeed causes hemolysis, but in terms of erythrocyte flow function, some conflicting results exist. ${ }^{1,2}$ With regard to $\mathrm{CPB}$, the focus of science has been on leukocytes and systemic inflammatory response, ${ }^{3,4}$ whereas the capillary flow function of blood remains an unexplored field. Of great interest are new observations about fat deposits in brain capillaries versus the reinfusion of pericardial suction blood. ${ }^{5}$ The possible role of activated leukocytes and platelets has also been discussed. ${ }^{6}$ We aimed at investigating the embolic potential of the different blood subcomponents. This was accomplished by using an in vitro narrow-pore flow model with diameter approximating the size of human capillaries.

\section{Materials and Methods}

Ten elective CPB cases were selected at random: 7 coronary artery bypass grafting, 1 aortic valve replacement, and 2 combined procedures. Blood was sampled before CPB (before anesthetic induction), 5 minutes after $\mathrm{CPB}$ onset, and at the end of $\mathrm{CPB}$. The $\mathrm{CPB}$ was of standard design: crystalloid antegrade cardioplegia, moderate hypothermia, no arterial filters, and recirculation of unprocessed pericardial suction blood. Of a $15-\mathrm{mL}$ blood sample, $250 \mu \mathrm{L}$ was used to determine differential blood cell counts, and the remaining was centrifuged ( 5 minutes at $1500 \mathrm{~g}$ ) for plasma removal. Plasma was saved for flow analysis (see below) and for plasma-free hemoglobin. The blood cells were then prepared to express its subcomponents. With the buffy coat remaining, the rest of the plasma was removed by means of centrifugation and washing in 2 cycles (Krebs-Ringer-HEPES buffer [KRH]). One third of

From the Department of Surgical and Perioperative Science, Cardiothoracic Surgery, Umeå University Hospital, Umeå, Sweden.

This work was supported by Swedish Society for Medical Research and funds of the Medical Faculty, University of Umeå, the Sahlberg Fund, Swedish Medical Research Council (12X-11204), Swedish Diabetes Association, Swedish Heart and Lung Foundation, and Northern Swedish Heart Foundation.

Received for publication April 26, 2001; accepted for publication June 18, 2001.

Address for reprints: Gunnar Engström, MD, PhD, Cardiothoracic Surgery, Department of Surgical and Perioperative Science, Umeå University Hospital, S-901 85 Umeå, Sweden (E-mail: gunnar.engstrom.us@ vll.se).

J Thorac Cardiovasc Surg 2002;123:381-3

Copyright (C) 2002 by The American Association for Thoracic Surgery

$0022-5223 / 2002 \$ 35.00+0 \quad \mathbf{1 2 / 5 4 / 1 1 8 2 7 0}$

doi: $10.1067 / \mathrm{mtc} .2002 .118270$ this blood was collected as sample A, with leukocytes remaining. The remaining blood was recentrifuged, with removal of the buffy coat, and resuspended as sample B. Sample B is the traditional method of leukocyte reduction and was used in historic CPB investigations. Half of sample B was filtered through a leukocyte-eliminating filter ${ }^{7}$ and referred to as sample $\mathrm{C}$, with only erythrocytes remaining. The narrow-pore flow characteristics of these samples and the plasma were measured with the KGE flowmeter (ESTRAB, Umeå, Sweden). ${ }^{8}$ This computer-assisted system with pneumatic valve control is used to measure the flow rate at high temporal resolution by means of communication with a digital balance. Polycarbonate membranes with $5-\mu \mathrm{m}$ capillaries were used. The flow curves were divided by means of blank filtration to express relative flow and with linear regression to find the initial filtration rate (IFR) and the capillary clogging slope (CS). Narrowpore filtrating of blood is a widely accepted method to simulate capillary flow with many clinical implications. ${ }^{9}$ Paired and unpaired Student $t$ tests were used, and changes were verified by means of analysis of variance testing.

\section{Results}

Minor hemolysis occurred, corresponding to $0.6 \%$ of the circulating erythrocytes at the end of CPB. The erythrocyte particle concentration dropped at $\mathrm{CPB}$ onset as a result of priming and provided correction for hemodilution (Table 1). Mainly the neutrophilic granulocytes increased during CPB. In Figure 1 the flow curves of the different blood subcomponents are displayed (ie, plasma, washed and resuspended whole blood cells, blood cells after traditional buffy-coat removal, and erythrocytes only). The plasma flow suggested that the CPB priming reduced the capillary relative viscosity (increased IFR, $P<.001$ ). However, plasma flow then decreased (in terms of both IFR and CS, $P<.05$ ) with further CPB. This response indicated particle contamination because the hemodilution remained constant. The pattern of whole blood cells suggested deteriorated capillary flow properties at the end of CPB (sample A; Figure 1, $B$; IFR, $P<.01$ ). This pattern remained when the traditional leukocyte buffy-coat removal was used (sample B, $P<.05)$. However, when all leukocytes were eliminated, the difference disappeared (sample C). The IFR and CS values are indicated in Table 2.

\section{Discussion}

Our data suggest that CPB indeed does impair the narrow-pore flow characteristics of blood and may therefore contribute to microembolization and CPB-related cognitive disorders. This was seen with resuspended whole blood cells and occurred at the end of CPB. The impaired capillary flow remained when the buffy coat was removed. In historic data this was misinterpreted as an erythrocyte-related change. ${ }^{1}$ In our preparation the buffy-coat aspiration 


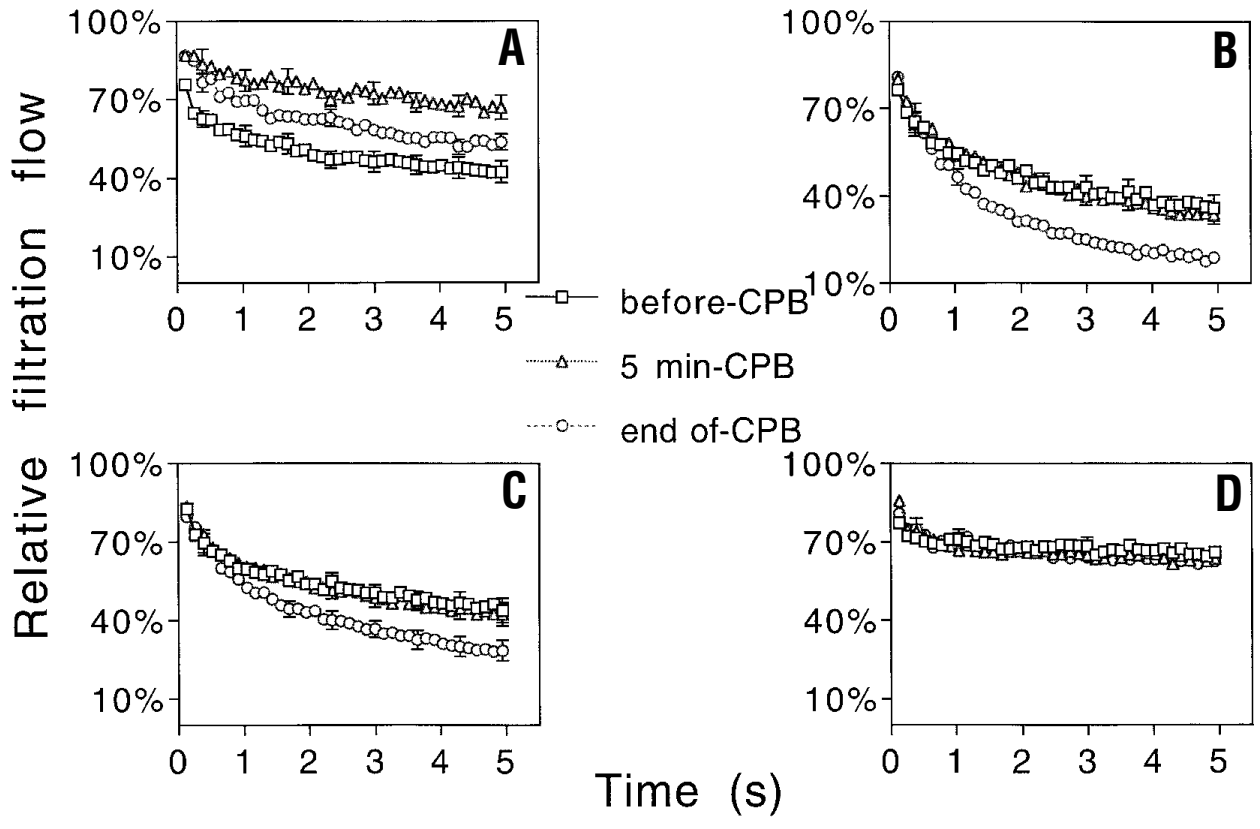

Figure 1. Relative flow of plasma and $5 \%$ hematocrit blood resuspensions as a function of time by using 5 - $\mu$ m polycarbonate membranes: A, plasma flow curve; B, the entire pool of washed whole blood cells was resuspended in KRH; C, the buffy coat was removed, and the remaining blood cells were washed and resuspended in KRH; D, the buffy coat was removed, and the blood was filtrated through a leukocyte-eliminating filter, followed by washing and resuspension of the erythrocytes in KRH. Values are means \pm SEM $(n=10)$. Error bars are given at 5-period intervals.

TABLE 1. Blood and cellular changes caused by CPB

\begin{tabular}{|c|c|c|c|c|c|c|}
\hline Parameter (unit) & $\begin{array}{l}\text { (1) Before CPB } \\
\text { (mean } \pm \text { SEM) }\end{array}$ & $\begin{array}{l}P \text { value } \\
\text { (2 vs } 1)\end{array}$ & $\begin{array}{l}\text { (2) 5-min CPB } \\
\text { (mean } \pm \text { SEM) }\end{array}$ & $\begin{array}{l}P \text { value } \\
\text { (3 vs 2) } \\
\end{array}$ & $\begin{array}{l}\text { (3) End of CPB } \\
\text { (mean } \pm \text { SEM) }\end{array}$ & $\begin{array}{l}P \text { value } \\
\text { (3 vs 1) }\end{array}$ \\
\hline \multicolumn{7}{|l|}{ Absolute values } \\
\hline $\mathrm{p}-\mathrm{Hb}(\mathrm{mg} / \mathrm{L})$ & $36 \pm 4$ & .05 & $79 \pm 19$ & $<.01$ & $501 \pm 104$ & $<.01$ \\
\hline Erythrocytes (1012/L) & $4.34 \pm 0.13$ & $<.001$ & $2.78 \pm 0.12$ & NS & $2.92 \pm 0.12$ & $<.001$ \\
\hline Leukocytes $\left(10^{9} / \mathrm{L}\right)$ & $5.60 \pm 0.57$ & $<.01$ & $3.89 \pm 0.36$ & $<.01$ & $8.14 \pm 0.81$ & $<.05$ \\
\hline Neutrophils (109/L) & $3.14 \pm 0.32$ & $<.01$ & $1.90 \pm 0.17$ & $<.001$ & $5.78 \pm 0.80$ & $<.05$ \\
\hline Lymphocytes (109/L) & $1.67 \pm 0.20$ & NS & $1.40 \pm 0.12$ & $<.01$ & $1.71 \pm 0.13$ & NS \\
\hline Monocytes (109/L) & $0.41 \pm 0.05$ & NS & $0.31 \pm 0.05$ & NS & $0.41 \pm 0.08$ & NS \\
\hline Eosinophils (109/L) & $0.30 \pm 0.07$ & NS & $0.18 \pm 0.04$ & NS & $0.20 \pm 0.05$ & NS \\
\hline Basophils $\left(10^{9} / \mathrm{L}\right)$ & $0.06 \pm 0.02$ & NS & $0.04 \pm 0.01$ & NS & $0.05 \pm 0.02$ & NS \\
\hline \multicolumn{7}{|c|}{ Values corrected for hemodilution } \\
\hline $\mathrm{p}-\mathrm{Hb}(\mathrm{mg} / \mathrm{L})$ & $36 \pm 4$ & $<.05$ & $133 \pm 30$ & $<.01$ & $746 \pm 154$ & $<.01$ \\
\hline Leukocytes (109/L) & $5.60 \pm 0.57$ & NS & $5.79 \pm 0.49$ & $<.001$ & $12.03 \pm 1.04$ & $<.001$ \\
\hline Neutrophils (109/L) & $3.14 \pm 0.32$ & NS & $2.92 \pm 0.24$ & $<.001$ & $8.49 \pm 1.05$ & $<.01$ \\
\hline Lymphocytes (109/L) & $1.67 \pm 0.20$ & $<.05$ & $2.14 \pm 0.15$ & $<.01$ & $2.56 \pm 0.20$ & $<.01$ \\
\hline Monocytes $\left(10^{9} / \mathrm{L}\right)$ & $0.41 \pm 0.05$ & NS & $0.48 \pm 0.08$ & NS & $0.61 \pm 0.12$ & NS \\
\hline Eosinophils (109/L) & $0.30 \pm 0.07$ & NS & $0.26 \pm 0.06$ & NS & $0.30 \pm 0.07$ & NS \\
\hline Basophils (109/L) & $0.06 \pm 0.02$ & NS & $0.06 \pm 0.02$ & NS & $0.08 \pm 0.03$ & NS \\
\hline
\end{tabular}

The upper panel of the table denotes absolute values, whereas in the lower panel the counts were adjusted for hemodilution at CPB onset (see "Materials and Methods" section). Values are given as means \pm SEM $(n=10) . p-H b$, Plasma hemoglobin; $N S$, not significant.

only removed $55 \%$ of the leukocytes, a problem known from the literature. ${ }^{7}$ When all leukocytes were eliminated with an absorbing filter, ${ }^{7}$ there was no detected difference with $\mathrm{CPB}$. The decrease in capillary flow hides 2 mechanisms: an increase in leukocyte count and possible leukocyte activation. Another concern was the plas- ma-flow pattern at the end of CPB, with changes in both IFR (indicating relative capillary viscosity) and slope (clogging particles). These particles are not blood cells but instead represent low-density contamination, such as fat cells, platelet aggregates, or cell debris. The model was very sensitive, and the 10 random CPB 
TABLE 2. Narrow-pore flow characteristics before and during CPB

\begin{tabular}{|c|c|c|c|c|c|c|}
\hline Suspension & $\begin{array}{l}\text { (1) Before CPB } \\
\text { (mean } \pm \text { SEM) }\end{array}$ & $\begin{array}{l}P \text { value } \\
\text { (2 vs } 1)\end{array}$ & $\begin{array}{l}\text { (2) 5-min CPB } \\
\text { (mean } \pm \text { SEM) }\end{array}$ & $\begin{array}{l}P \text { value } \\
\text { (3 vs 2) }\end{array}$ & $\begin{array}{l}\text { (3) End of CPB } \\
\text { (mean } \pm \text { SEM) }\end{array}$ & $\begin{array}{l}P \text { value } \\
\text { (3 vs 1) }\end{array}$ \\
\hline \multicolumn{7}{|l|}{ IFR ( $\%$ of KRH blank) } \\
\hline Plasma & $53.1 \pm 3.6$ & $<.001$ & $77.0 \pm 4.1$ & $<.05$ & $66.0 \pm 2.1$ & $<.01$ \\
\hline (A) Leukocytes remaining & $50.3 \pm 1.6$ & NS & $51.3 \pm 2.3$ & $<.01$ & $37.4 \pm 2.0$ & $<.01$ \\
\hline$P$ value (A vs $B)$ & $<.05$ & & NS & & $<.05$ & \\
\hline (B) Buffy coat removed & $57.6 \pm 2.3$ & NS & $57.8 \pm 2.5$ & $<.05$ & $47.9 \pm 2.9$ & $<.05$ \\
\hline$P$ value (B vs $\mathrm{C}$ ) & $<.01$ & & $<.05$ & & $<.001$ & \\
\hline (C) Erythrocytes only & $69.0 \pm 2.0$ & NS & $66.8 \pm 1.5$ & NS & $68.2 \pm 2.0$ & NS \\
\hline \multicolumn{7}{|l|}{ CS ( $\%$ of KRH blank/s) } \\
\hline Plasma & $-3.09 \pm 0.62$ & NS & $-2.77 \pm 0.57$ & $<.05$ & $-3.86 \pm 0.48$ & NS \\
\hline (A) Leukocytes remaining & $-4.13 \pm 1.00$ & NS & $-5.30 \pm 0.70$ & NS & $-5.86 \pm 0.62$ & NS \\
\hline$P$ value (A vs $B)$ & NS & & NS & & NS & \\
\hline (B) Buffy coat removed & $-3.75 \pm 0.61$ & NS & $-4.51 \pm 0.57$ & $<.05$ & $-5.83 \pm 0.56$ & $<.01$ \\
\hline$P$ value (B vs C) & $<.001$ & & $<.01$ & & $<.001$ & \\
\hline (C) Erythrocytes only & $-0.89 \pm 0.16$ & NS & $-0.93 \pm 0.72$ & NS & $-1.72 \pm 0.41$ & NS \\
\hline
\end{tabular}

IFR and CS were calculated for the different CPB groups and blood preparations, as described in the legend to Figure 1. IFR and CS were derived by means of linear regression of the individual relative filtration curves (blood flow vs KRH blank) between 1.2 and 5 seconds. Values are means $\pm S E M(n=10)$. NS, Not significant.

cases had significant outcomes. The experimental model is not sensitive to platelets, erythrocyte aggregation does not occur because the sample was free from plasma, and lysed cells were removed by washing.

Blauth and coworkers ${ }^{10}$ demonstrated vessel occlusion in the retina during $\mathrm{CPB}$ by using fluorescein retinal angiography. It is possible that these embolic particles would become trapped in our model. The model may provide useful information for in vitro monitoring of capillary blood function during CPB. Of particular interest is arterial-line filters and processing of pericardial suction blood.

\section{References}

1. Hirayama T, Yamaguchi H, Allers M, Roberts D. Evaluation of red cell damage during cardiopulmonary bypass. Scand J Thorac Cardiovasc Surg. 1985;19:263-5.

2. Reinhart WH, Ballmer PE, Rohner F, Ott P, Straub PW. The influence of extracorporeal circulation on erythrocytes and flow properties of blood. J Thorac Cardiovasc Surg. 1990;100:538-45.
3. Taylor KM. Brain damage during cardiopulmonary bypass. Ann Thorac Surg. 1998;65(Suppl 1):20-6.

4. Lazar HL, Zhang X, Hamasaki T, Treanor P, Rivers S, Bernard S, et al. Role of leukocyte depletion during cardiopulmonary bypass and cardioplegic arrest. Ann Thorac Surg. 1995;60:1745-8.

5. Brooker RF, Brown WR, Moody DM, Hammon JW Jr, Reboussin DM, Deal DD, et al. Cardiotomy suction: a major source of brain lipid emboli during cardiopulmonary bypass. Ann Thorac Surg. 1998;65: 1651-5.

6. Utley JR. Cardiopulmonary bypass surgery. Curr Opin Cardiol. 1992; 7:267-75.

7. Lindmark K, Engström KG. Use of polyester leukocyte elimination filters in blood filterability research. Biorheology. 1998;35:131-40.

8. Lindmark K, Engström KG. Analysis of flow acceleration during erythrocyte filtration: dependence of hematocrit and cell rigidity. Biorheology. 1996;33:379-95.

9. Mokken FC, Kedaria M, Henny CP, Hardeman MR, Gelb AW. The clinical importance of erythrocyte deformability, a hemorheological parameter. Ann Hematol. 1992;64:113-22.

10. Blauth C, Arnold J, Kohner EM, Taylor KM. Retinal microembolism during cardiopulmonary bypass demonstrated by fluorescin angiography. Lancet. 1986;2:837-9. 